Check for updates

Cite this: RSC Adv., 2019, 9, 38687

Received 27th September 2019 Accepted 7th November 2019

DOI: $10.1039 / c 9 r a 07860 f$

rsc.li/rsc-advances

\title{
Fused pyrazole-phenanthridine based dyads: synthesis, photo-physical and theoretical studies, and live cell $\mathrm{pH}$ imaging $\dagger$
}

\author{
Venkatesan Muthukumar, ${ }^{a}$ Sathishkumar Munusamy, ${ }^{b}$ Krishnan Thirumoorthy, \\ Sathish Sawminathan ${ }^{a}$ and Sathiyanarayanan Kulathulyer (D) *a
}

\begin{abstract}
The arrangement of small sized molecules with a scaffold structure plays an active role in the fields of sensors and health care. An efficient molecular design strategy for four pyrazole-phenanthridine based $D-\pi-A$ luminophores, denoted as $2 a, 2 b, 2 c$ and $2 d$ was developed to investigate the effect of acid on the photo-physical properties of these dyes. Photo-physical studies of the synthesized probes showed distinct absorption and emission under various $\mathrm{pH}$ conditions. Theoretical calculations using density functional methods were carried out for understanding the mechanistic aspects of the proton induced fluorescence. The experimentally observed photo-physical properties correlated well with theoretical results. Moreover, probes 2 and 2 a can be used to monitor the fluorescence changes in E. coli cells under different $\mathrm{pH}$ conditions.
\end{abstract}

\section{Introduction}

Functional organic compounds, especially, stimuli-responsive organic emissive materials, have gained considerable attention in materials science, ${ }^{1-8}$ medicine, ${ }^{9-12}$ biology ${ }^{13-16}$ and environmental analytics. ${ }^{17-21}$ Among them, the acidochromic materials, whose emission response depends on the $\mathrm{pH}$ of the medium, have received considerable attention because they find applications in various fields of scientific research such as environment, ecology, agriculture, and biological processes. Facile and accurate measurement of $\mathrm{pH}$ is essential to study many chemical and physiological processes including the regulation mechanisms of cells. Among the various analytical methods, fluorescence pH sensors have many advantages such as high sensitivity and selectivity, rapid response, and low cost. ${ }^{22,23}$ Most of the fluorescence probes for $\mathrm{pH}$ sensing, can sense in the "on-off (or off-on)"mode ${ }^{24-28}$ and are less advantageous than "off-on-off" sensors. Unfortunately, the development of "off-on-off" sensors demands complex molecular design to meet the structural and electronic properties. Fluorescence probes to sense $\mathrm{pH}$, based on various fluorophores such as xanthenes, BODIPY, cyanine, rhodamine, and phthalimide ${ }^{29-34}$ have been developed. However, these sensors lack the

${ }^{a}$ Chemistry Department, School of Advanced Sciences, Vellore Institute of Technology University, Vellore-632014, Tamil Nadu, India. E-mail: venket.chem88@gmail.com ${ }^{b}$ Institute of Physical Sciences, National Autonomous University of Mexico, Mexico $\dagger$ Electronic supplementary information (ESI) available. CCDC 1561810 and 1561812. For ESI and crystallographic data in CIF or other electronic format see DOI: $10.1039 / \mathrm{c} 9 \mathrm{ra} 07860 \mathrm{f}$ key qualities such as photostability of the probe and reversibility.

Our ongoing research program is on the development of fluorescent probes for multifield applications. ${ }^{35-37}$ Among the various probes that we developed, phenanthridine based materials are significant because of their tunable fluorescence nature. Recently, we have developed functionalized phenanthridine based probe for the selective detection $\mathrm{Ru}(\mathrm{III}) .{ }^{38}$ In the current work, we report the facile synthesis, characterization and studies on pH sensing ability of fused pyrazolephenanthridine derivatives. The characterization of the synthesized molecules was carried out by different spectroscopic techniques and X-ray crystallography to confirm the structure of the probes. In the synthesized probe, both pyridine and pyrazole act as donor moiety, which results in weak fluorescence. The synthesized probe undergoes protonation over the addition of $\mathrm{H}^{+}$which results in the formation of pyridinium ion. The formation of pyridinium ion yielded $\mathrm{D}-\pi-\mathrm{A}$ type dyes with intramolecular charge transfer (ICT) emission (Fig. 1) in which pyrazole acts as a donor and pyridinium ion acts as an

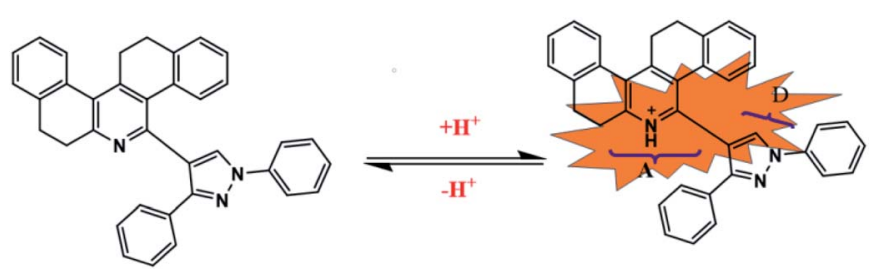

Fig. 1 Structure of the synthesized probe and design rational. 
acceptor. The induced color change is visible even to the naked eye. In addition, the greenish yellow fluorescence induced by trifluoroacetic acid can be reversed to its original fluorescence over the addition of triethylamine. More importantly, the synthesized probes have excellent selectivity towards $\mathrm{H}^{+}$over other metal ion and another competitive moiety. The synthesized probes have excellent cell permeability, and are applied successfully to monitor $\mathrm{pH}$ fluctuations in living cells. Computational studies are gaining great interest from the experimentalist view point to speculate various aspects in interpreting the experimental results. The use of Density Functional Theory (DFT) and Time-Dependent DFT (TDDFT) methods have been prominent in recent times for predicting the photo-physical properties and they are widely found in the literature. $^{39-41}$ In particular, the photo-physical studies of different compounds to understand the unexpected solvent effect and acidochromic fluorescence were reported elsewhere. In view of that, theoretical calculations were carried out for the molecules of our interest, such as probe $\mathbf{2 a}$ and $\mathbf{2 b}$ with implicit solvation model first. Further, one TFA molecule is explicitly considered to observe the intermolecular interaction with $\mathbf{2 a}$ and $2 \mathbf{b}$ separately, and is named as 2a-TFA and 2b-TFA, which would eventually shed light on the experimentally observed photo-physical properties.

\section{Experimental section}

\section{Chemicals and apparatus}

Starting material used for synthesis and solvents for the analytical use were bought from commercial sources and were used as such without any further purification. The molecular weight of the compound was obtained using JEOL GCMATE mass spectrometer. ${ }^{1} \mathrm{H}$ and ${ }^{13} \mathrm{C}$ NMR was obtained using Bruker Ascend III $400 \mathrm{MHz}$ spectrometer using $\mathrm{CDCl}_{3}$, UV spectra were recorded using Shimadzu 3600 spectrometer with a quartz cell (path length $=1 \mathrm{~cm}$ ) at room temperature. Emission spectra were recorded using Hitachi High Technologies spectrometer. Single crystal X-ray diffraction was carried out with Bruker Kappa APEXII.

\section{Procedure for the synthesis of probes and characterization}

Compound $\mathbf{1}$ and its derivatives were synthesized according to the procedure stated in literature, ${ }^{49}$ while compound 2 was prepared according to the following procedure. In an oven dried conical flask, ammonium acetate was $(2 \mathrm{mmol})$ taken and dissolved in ethanol solvent. To this, compound 1 was added (2 $\mathrm{mmol}$ ) and warmed. To this reaction mixture, two equivalents of 2-tetralone were added and the reaction mixture was stirred overnight. The completion of the reaction was monitored by TLC. Column chromatography was carried out for the reaction mixture over silica gel. Compound 2 was separated in $2 \%$ ethyl acetate in hexane. Yield: $65 \% .{ }^{1} \mathrm{H}$ NMR and ${ }^{13} \mathrm{C}$ were recorded by dissolving compounds in $\mathrm{CDCl}_{3}$ solvent. Chemical shifts $(\delta)$ are given in ppm relative to TMS internal standard.

1,3-Diphenyl-1H-pyrazole-4-yl-7,8,13,14-tetrahydrodibenzo $[a, i]$ phenanthridine (2a). ${ }^{1} \mathrm{H}$ NMR (400 MHz, $\left.\mathrm{CDCl}_{3}\right): \delta 8.32(\mathrm{~s}$,
1H), 7.87-7.85 (d, $J=8 \mathrm{~Hz}, 2 \mathrm{H}), 7.72-7.68(\mathrm{q}, J=16 \mathrm{~Hz}, 3 \mathrm{H})$, $7.42-7.40(\mathrm{~d}, J=8 \mathrm{~Hz}, 1 \mathrm{H}), 7.34-7.33(\mathrm{t}, J=4 \mathrm{~Hz}, 3 \mathrm{H}), 7.22-7.20$ $(\mathrm{d}, J=8 \mathrm{~Hz}, 1 \mathrm{H}), 7.17-7.16(\mathrm{~d}, J=4 \mathrm{~Hz}, 2 \mathrm{H}), 7.10-7.06(\mathrm{~d}, J=$ $16 \mathrm{~Hz}, 3 \mathrm{H}), 7.06-6.99(\mathrm{~m}, 1 \mathrm{H}), 7.00-6.99$ (d, $J=4 \mathrm{~Hz}, 1 \mathrm{H}), 6.97-$ $6.91(\mathrm{~m}, 2 \mathrm{H}), 3.17-3.14(\mathrm{t}, J=12 \mathrm{~Hz}, 3 \mathrm{H}), 3.07-3.04(\mathrm{t}, J=12 \mathrm{~Hz}$, $4 \mathrm{H}), 2.41-2.37$ (p, $J=20 \mathrm{~Hz}, 2 \mathrm{H}) .{ }^{13} \mathrm{CNMR}$ (400 MHz, $\mathrm{CDCl}_{3}$ ): $\delta 158.3,158.6,151.6,145.9,145.5,140.0,139.5,138.5,136.8$, $133.0,132.9,129.7,129.0,128.7,128.3,128.0,127.9,127.7$, $127.5,127.3,127.2,127.1,127.0,126.85,126.5,126.4,126.3$, 126.1, 125.8, 123.1, 121.2, 118.9, 112.9, 33.1, 31.3, 30.9, 29.5, 29.0, 28.7. The obtained mass value for compound $\mathbf{2 a}$ is $502.2202 \mathrm{~m} / \mathrm{z}$ (ESI Fig. $17 \dagger)$.

5-(1-(4-Methoxyphenyl)-3-phenyl-1H-pyrazole-4-yl)-7,8,13,14tetrahydrodibenzo $[\boldsymbol{a}, \boldsymbol{i}]$ phenanthridine $(2 \mathrm{~b}) .{ }^{1} \mathrm{H}$ NMR $(400 \mathrm{MHz}$, $\left.\mathrm{CDCl}_{3}\right): \delta 8.23(\mathrm{~s}, 1 \mathrm{H}), 7.81-7.79(\mathrm{~d}, J=8 \mathrm{~Hz}, 2 \mathrm{H}), 7.49-7.45(\mathrm{q}, J$ $=16 \mathrm{~Hz}, 4 \mathrm{H}), 7.37-7.35(\mathrm{~d}, J=8 \mathrm{~Hz}, 1 \mathrm{H}), 7.31-7.27$ (p, $J=20 \mathrm{~Hz}$, $3 \mathrm{H}), 7.18-7.16(\mathrm{~d}, J=8 \mathrm{~Hz}, 1 \mathrm{H}), 7.09-7.07$ (d, $J=8 \mathrm{~Hz}, 2 \mathrm{H}), 7.00-$ $6.96(\mathrm{q}, J=16 \mathrm{~Hz}, 1 \mathrm{H}), 6.93-6.88(\mathrm{~m}, 2 \mathrm{H}), 6.59-6.57$ (d, $J=8 \mathrm{~Hz}$, $2 \mathrm{H}), 6.94-6.91(\mathrm{t}, J=12 \mathrm{~Hz}, 2 \mathrm{H}), 3.69(\mathrm{~s}, 3 \mathrm{H}), 3.11-3.08$ (q, $J=$ $16 \mathrm{~Hz}, 3 \mathrm{H}$ ), 3.02-3.01 (d, $J=4 \mathrm{~Hz}, 3 \mathrm{H}), 2.41-2.38$ (q, $J=16 \mathrm{~Hz}$, 2H), $2.16(\mathrm{~s}, 6 \mathrm{H}) ;{ }^{13} \mathrm{CNMR}\left(400 \mathrm{MHz}, \mathrm{CDCl}_{3}\right): \delta 206.9,159.0$, 158.3 , 146.1, 145.4, 140.0, 139.5, 138.5, 133.0, 132.9, 129.3, $128.7,128.4,127.9,127.76,127.72,127.30,127.05,126.47$, 126.20, 126.12, 125.89, 125.87, 123.51, 118.89, 113.47, 113.19, 77.42, 77.30, 77.10, 76.78, 55.27, 33.20, 30.94, 29.53, 29.16, 29.0. The obtained mass value for compound 2a is $502.2202 \mathrm{~m} / \mathrm{z}$ (ESI Fig. 18†).

5-(1-(4-Bromophenyl)-3-phenyl-1H-pyrazole-4-yl)-7,8,13,14tetrahydrodibenzo[ $[\boldsymbol{a}, \boldsymbol{i}]$ phenanthridine $(2 \mathrm{c}) .{ }^{1} \mathrm{H}$ NMR $(400 \mathrm{MHz}$, $\left.\mathrm{CDCl}_{3}\right): \delta 8.27(\mathrm{~s}, 1 \mathrm{H}), 7.81-7.79(\mathrm{~d}, J=8 \mathrm{~Hz}, 2 \mathrm{H}), 7.48-7.44(\mathrm{q}, J$ $=12 \mathrm{~Hz}, 4 \mathrm{H}), 7.38-7.35(\mathrm{t}, J=12 \mathrm{~Hz}, 1 \mathrm{H}), 7.30-7.28(\mathrm{~d}, J=8 \mathrm{~Hz}$, $3 \mathrm{H}), 7.16-7.11(\mathrm{~m}, 3 \mathrm{H}), 7.01-6.99(\mathrm{t}, J=12 \mathrm{~Hz}, 3 \mathrm{H}), 6.96-6.94(\mathrm{~d}$, $J=8 \mathrm{~Hz}, 5 \mathrm{H}), 3.11-3.01(\mathrm{~m}, 6 \mathrm{H}), 2.41-2.39(\mathrm{t}, J=12 \mathrm{~Hz}, 2 \mathrm{H}) .{ }^{13} \mathrm{C}$ NMR (400 MHz, $\left.\mathrm{CDCl}_{3}\right): \delta 158.5,150.3,145.56,145.5,139.9$, 139.5 , 132.9, 132.0, 130.6, 129.4, 128.8, 127.9, 127.8, 127.3, 127.2, 126.5, 126.1, 125.9, 123.8, 121.4, 119.0, 33.1, 30.9, 29.5, 29.0 .

5-(1-(4-Methoxyphenyl)-3-phenyl-1H-pyrazole-4-yl)-7,8,13,14tetrahydrodibenzo $[\boldsymbol{a}, \boldsymbol{i}]$ phenanthridine $(2 \mathrm{~d}) .{ }^{1} \mathrm{H}$ NMR $(400 \mathrm{MHz}$, $\left.\mathrm{CDCl}_{3}\right): \delta 9.24(\mathrm{~s}, 1 \mathrm{H}), 8.88-8.86(\mathrm{~d}, J=8 \mathrm{~Hz}, 1 \mathrm{H}), 8.21-8.19(\mathrm{~d}, J$ $=8 \mathrm{~Hz}, 1 \mathrm{H}), 8.06-8.00(\mathrm{~m}, 3 \mathrm{H}), 7.87-7.85(\mathrm{~d}, J=8 \mathrm{~Hz}, 1 \mathrm{H}), 7.80$ $(\mathrm{s}, 1 \mathrm{H}), 7.77(\mathrm{~s}, 1 \mathrm{H}), 7.75(\mathrm{~s}, 1 \mathrm{H}), 7.73-7.71(\mathrm{~d}, J=8 \mathrm{H}, 1 \mathrm{H}), 7.69$ $(\mathrm{s}, 1 \mathrm{H}), 6.64-6.61(\mathrm{t}, J=12 \mathrm{~Hz}, 1 \mathrm{H}), 7.58-7.57(\mathrm{~d}, J=4 \mathrm{~Hz}, 1 \mathrm{H})$, $7.53(\mathrm{~s}, 1 \mathrm{H}), 7.49(\mathrm{~s}, 1 \mathrm{H}), 7.36-7.31(\mathrm{~m}, 1 \mathrm{H}), 2.17(\mathrm{~s}, 3 \mathrm{H}), 1.25(\mathrm{~s}$, $3 \mathrm{H}) .{ }^{13} \mathrm{C} \mathrm{NMR}\left(400 \mathrm{MHz}, \mathrm{CDCl}_{3}\right): \delta$ 135.7, 133.6, 131.2, 129.5, $129.1,128.9,128.6,126.9,126.8,123.3,126.1,125.7,125.2$, $125.0,123.4,123.2,121.3,121.1,121.0,120.1,119.5,116.7$, $112.8,105.5,30.9,29.7,29.3,14.15$.

\section{Computational calculation methods}

Computational chemistry calculations were carried out to understand the experimentally observed photo-physical properties in TFA solvent polarity. The reported molecules in the present work such as $\mathbf{2 a}, \mathbf{2 b}, \mathbf{2 a - T F A}$ and $\mathbf{2 b}$-TFA were first optimized in gas phase and later in solution phase by considering the dielectric medium of the TFA solvent. The structural optimization of 2a, 2b, 2a-TFA and 2b-TFA 
molecules was carried out using DFT methods. In DFT, the well-known exchange-correlation functional (XC) function, Becke 3-parameter (B3) combined with Lee-Yang-Parr (LYP $)^{\mathbf{4 2 , 4 3}}$ correlation functional, popularly called as B3LYP was utilized in the present work. The B3LYP functional with 6$31+G^{*}$ split valence basis set was used for all the computational calculations. The integral equation formalism (IEF) version of the polarizable continuum model $(\mathrm{PCM})^{\mathbf{4 4}}$ was employed to incorporate the solvent effects in the computational calculations. The ground state optimized geometries obtained in gas phase and also in TFA solvent phase were used separately to find the singlet excited state structure of $\mathbf{2 a}, \mathbf{2 b}$, 2a-TFA and 2b-TFA molecules with TDDFT ${ }^{\mathbf{4 5 , 4 6}}$ method. All TDDFT calculations were carried out using single point calculation from optimized geometries of $2 \mathbf{a}, 2 \mathbf{b}, 2 \mathbf{a}-\mathbf{T F A}$ and $2 \mathbf{b}$-TFA at $\mathrm{B} 3 \mathrm{LYP} / 6-31+\mathrm{G}^{*}$ level of theory. The positive frequencies obtained from the normal mode analysis for all ground state geometries ascertained that all the optimized structures were in their global minimum. All the quantum chemical calculations were performed with Gaussian 09W package. ${ }^{47}$ The structures and electron density plots were obtained with help of GaussView 5.0 program. $^{48}$

\section{Cell toxicity assay evaluation}

The cytotoxicity of compound $2 \mathbf{a}$ and $2 \mathbf{b}$ against $E$. coli bacteria was estimated using liquid Luria-Bertani medium (LB). From this $400 \mu \mathrm{L}$ of freshly prepared $E$. coli culture $(10 \mathrm{~h})$ was centrifuged at $3000 \mathrm{rpm}$ for $20 \mathrm{~min}$ at $4{ }^{\circ} \mathrm{C}$. Supernatant liquid Luria-Bertani medium (LB) was removed, and the pellet containing bacterial cells was washed twice with $800 \mu \mathrm{L}$ PBS (150 mM NaCl, pH 7.4) followed by centrifugation at $3000 \mathrm{rpm}$ for $20 \mathrm{~min}$ at $4{ }^{\circ} \mathrm{C}$. The pellet with bacterial cells alone is used as control. The final pellet containing purified bacterial cells were mixed with $50 \mu \mathrm{L}$ PBS containing probe $2 \mathrm{a}$ (in $1: 1 \mathrm{v} / \mathrm{v}$ THFwater). In this absorbance was monitored by microplate reader. The cell viability was expressed by the difference in absorbance of samples and control. This same procedure was repeated for the compound $\mathbf{2 b}$ also. The percentage of cell growth inhibition was calculated by the following formula $\%$ cytotoxicity $=100-$ $\%$ cell viability.

\section{Results and discussion}

\section{Design and synthesis}

The synthesis of (1,3-diphenyl-1H-pyrazole-4-yl)-7,8,13,14-tetrahydrodibenzo[a,i]phenanthridine is outlined in Scheme 1. Precursor 1a and its derivatives1b-d were prepared by following the literature procedure. Probes 2a-d, the subject material, were facilely synthesized by the reaction of the respective aldehydes $\mathbf{1 a - d}$ with $\beta$-tetralone and ammonium acetate following a method that was previously reported by our research group. All the synthesized compounds were thoroughly characterized by ${ }^{1} \mathrm{H}$ NMR, ${ }^{13} \mathrm{C}$ NMRand mass spectroscopy. Compound $\mathbf{2}$ and $\mathbf{2 a}$ was recrystallized by a slow evaporation method using ethanol-THF mixture and the

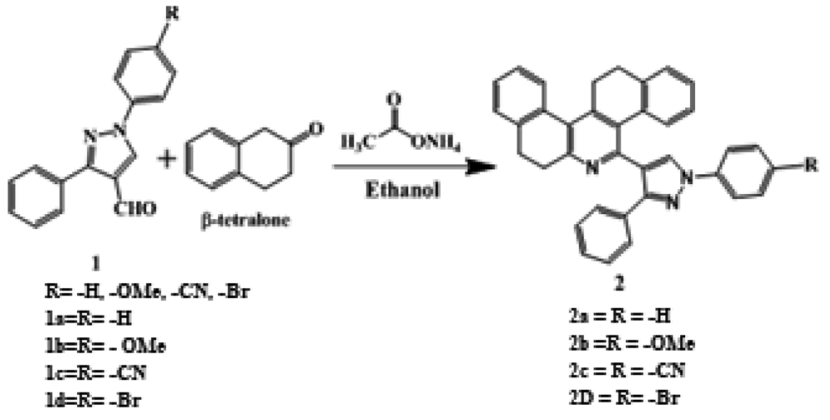

Scheme 1 Synthesis of probe 2 .

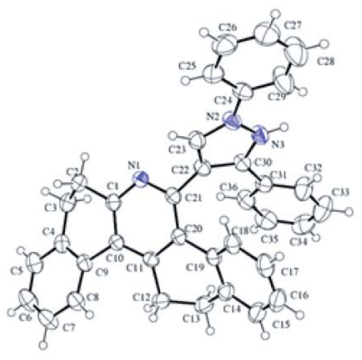

$2 a$

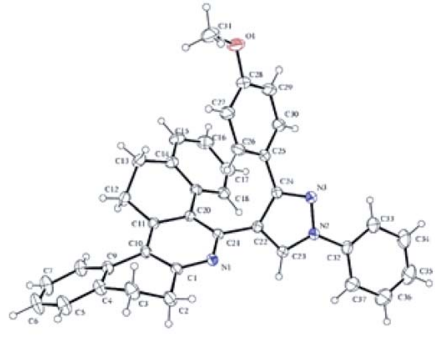

$2 \mathbf{b}$
Fig. 2 Crystal structure of compound $2 \mathrm{a}$ and $2 \mathrm{~b}$

crystal structure of the compound was elucidated using the $\mathrm{X}$ ray diffraction technique (Fig. 2).

Probes 2a-d was designed to have a phenanthridine fluorophore capable of interacting with $\mathrm{H}^{+}$and pyrazole, which was an electron donor that weakened the emission of phenanthridine. It was designed in a manner that when the probe interacted with $\mathrm{H}^{+}$, the subsequent formation of pyridinium ion induced D- $\pi-\mathrm{A}$ type of ICT system and the fluorescence of the probe would be switched on. The pyridinium ion state of the probe can be brought back to pyridine state by introducing triethylamine (TEA) and the fluorescence can be turned off.

\section{Influence of $\mathrm{H}^{+}$on the absorption and emission properties of the probes}

The optical property of the acid sensitive molecule can be perturbed by the change in electronic delocalization in a molecule over the addition of protons. Generally, the nitrogen hetero atom containing fluorophores is responsible for acidochromism because of the availability of the lone pair of electrons on the nitrogen to bind with protons. In order to study the acidochromic property of the synthesized molecules, we analysed the proton-sensing ability of the compounds $\mathbf{2 a - 2 d}$, which arise from the proton binding property of pyridine moiety. The normalized UV-vis absorption of compounds 2 a to $2 \mathbf{d}$ is shown in Fig. $\mathrm{S} 19 \dagger$ and their related photo-physical parameters are given in Tables 1 and 2. Distinct effects of substituent on their electronic properties, such as, large Stokes shift (1: $151 \mathrm{~nm} ; 2$ : $130 \mathrm{~nm}$; 3: $176 \mathrm{~nm}$ ) and high molar absorptions were observed. Compound $\mathbf{2 a}$ and $\mathbf{2 b}$ exhibited similar absorption spectra with 
Table 1 Photo-physical parameters of compound 2a, 2b, 2c and $2 \mathrm{~d}$ before the addition of TFA

\begin{tabular}{llllrl}
\hline & & $\begin{array}{l}\varepsilon_{\max } \times 10^{4} \\
\left(\mathrm{M}^{-1} \mathrm{~cm}^{-1}\right)\end{array}$ & $\lambda_{\mathrm{em}}{ }^{a}(\mathrm{~nm})$ & $\mathrm{SS}^{b}$ & $\Phi_{\mathrm{f}}{ }^{c}$ \\
\hline 2a & 267,320 & $2.70,1.00$ & $392,414,446$ & 125 & 0.20 \\
2b & 267,320 & $2.75,1.07$ & 397 & 130 & 0.17 \\
2c & 271,367 & $2.15,0.25$ & $369,386,405$ & 98 & 0.23 \\
2d & 271,367 & $2.05,0.41$ & $368,386,407$ & 97 & 0.15
\end{tabular}

${ }^{a}$ Emission wavelength. ${ }^{b}$ Stocks shift. ${ }^{c}$ Quantum yield.

Table 2 Photo-physical parameters of compound $2 \mathrm{a}, 2 \mathrm{~b}, 2 \mathrm{c}$ and $2 \mathrm{~d}$ after the addition of TFA

\begin{tabular}{lllll}
\hline & $\begin{array}{l}\lambda_{\text {abs }} \\
(2+\text { TFA })(n m)\end{array}$ & $\begin{array}{l}\lambda_{\text {em }} \\
(2+\text { TFA })(n m)\end{array}$ & $\begin{array}{l}\text { SS } \\
(2+\text { TFA })(n m)\end{array}$ & $\begin{array}{l}\Phi_{\mathrm{f}} \\
(2+\text { TFA })\end{array}$ \\
\hline 2a & 279,315 & 463 & 196 & 0.11 \\
2b & 265,318 & 457 & 190 & 0.07 \\
2c & 270,367 & - & - & - \\
2d & - & - & - & - \\
\hline
\end{tabular}

two distinct absorption maxima. The peak at $269 \mathrm{~nm}$ was due to the $\mathrm{n}-\pi^{*}$ transition and the peak at 320 is attributed to the $\pi-\pi^{*}$ transition. However, in compound $2 \mathbf{c}$ and $\mathbf{2 d}$, the absorption peak responsible for $\mathrm{n}-\pi^{*}$ transition had slight bathochromic shift and appeared at $270 \mathrm{~nm}$ and $272 \mathrm{~nm}$ respectively. Furthermore, the $\pi-\pi^{*}$ transition had phenomenal redshift and appeared in the region of $367 \mathrm{~nm}$. This can be explained on the basis of their extended conjugation and development of ICT due to the presence of electron donating $(-\mathrm{Br})$ and withdrawing (-CN) groups.

We initially evaluated the changes in the UV-visible spectrum of probes with and without the addition of $\mathrm{H}^{+}$. In this study, trifluoroacetic acid (TFA) was chosen as the acid source. Probe 2a was dissolved in chloroform solvent and the absorption spectra were recorded. To this solution, when TFA was added, the intensity of the peak at $267 \mathrm{~nm}$ progressively decreased with bathochromic shift and the peak at $320 \mathrm{~nm}$ completely disappeared (Fig. 3). In addition, a new peak originated at the excitation wavelength of $367 \mathrm{~nm}$. This clearly indicated that intramolecular charge transfer was induced over the addition of TFA. Considering the new absorption at ca. $367 \mathrm{~nm}$, TFA-protonated 2a in $\mathrm{CHCl}_{3}$ formed the cation 2a$\mathbf{H}^{+}$. As shown in Fig. 3C, the ratio of absorption at $267 \mathrm{~nm}$ to that at $367 \mathrm{~nm}, A_{269} / A_{367}$ had good linear relationship with the increasing concentration of TFA for up to 10 equivalents. Furthermore, these absorption changes can be significantly reversed on neutralization with bases such as triethylamine (TEA). Almost similar absorption spectral changes were observed for $\mathbf{2 b}$ upon the addition of TFA and TEA. Unfortunately, the absorption of the probes $\mathbf{2 c}$ and $\mathbf{2 d}$ was not affected by the TFA. Hence, further studies were carried out using only probes $\mathbf{2 a}$ and $\mathbf{2 b}$.

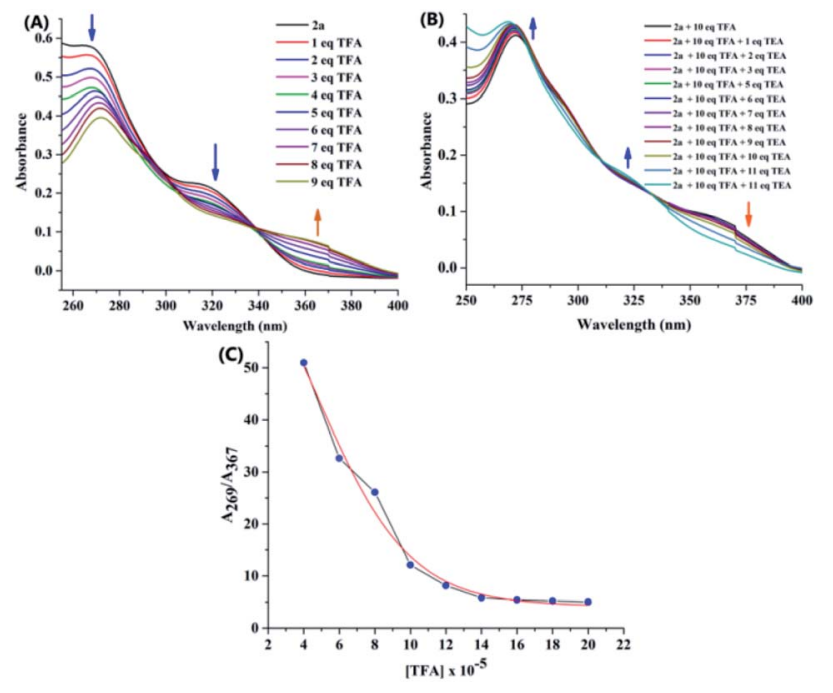

Fig. 3 (A) The absorption spectra of the compound $2 \mathrm{a}\left(2 \times 10^{-5}\right)$ in chloroform solvent over the addition of TFA. (B) The absorption spectra of the compound $2 \mathrm{~b}$ with TFA over the addition of TEA. (C) The plot of abortion intensity ratio $\left(A_{269} / A_{367}\right)$ vs. the concentration of TFA.

Fig. S21 $\uparrow$ shows the normalized emission spectra of the probes $2 \mathbf{a}$ and $2 \mathbf{b}$ at concentration $5 \times 10^{-5} \mathrm{M}$ in chloroform solvent. When excited at $269 \mathrm{~nm}$, probe $2 \mathrm{a}$ exhibited three intense peaks at $392 \mathrm{~nm}, 414 \mathrm{~nm}$ and a shoulder peak at $446 \mathrm{~nm}$, whereas, probe $\mathbf{2 b}$ displayed an intense emission at
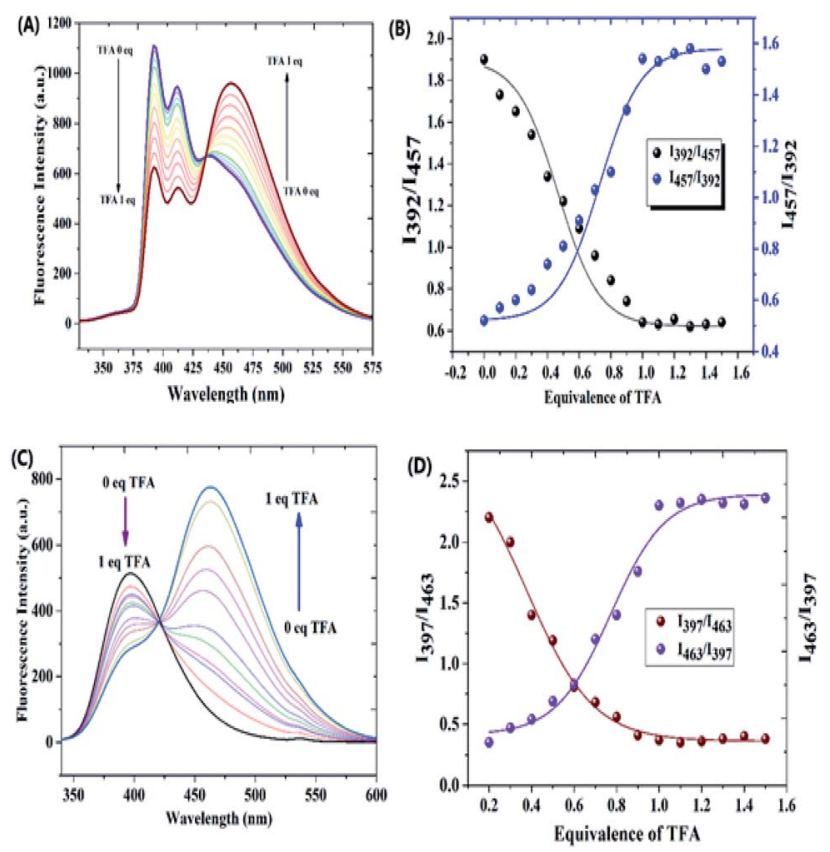

Fig. 4 (A) Emission spectra of the compound $2 \mathrm{a}\left(2 \times 10^{-5}\right)$ in chloroform solvent over the addition of TFA ( $\lambda_{\mathrm{ex}}=267 \mathrm{~nm}$ ). (B) Sigmoidal fitting of fluorescence intensity ration $/ 392 / I_{457} V s$. equivalence of TFA for compound 2a. (C) Emission spectra of the compound $2 \mathrm{~b}\left(2 \times 10^{-5}\right)$ in chloroform solvent over the addition of TFA ( $\left.\lambda_{\mathrm{ex}}=267 \mathrm{~nm}\right)$. (D) Sigmoidal fitting of fluorescence intensity ration $I_{397} / I_{463} \mathrm{Vs}$. equivalence of TFA for compound $2 \mathrm{a}$. 
$397 \mathrm{~nm}$. The extended conjugation in the pyrazole ring due to the presence of the methoxy group could be the reason behind the red-shifted emission maxima. The emission spectra of the compound $\mathbf{2 a}$ and $\mathbf{2 b}$ underwent significant ratiometric changes over the addition of TFA. The corresponding spectra are shown in Fig. 4A and C. In the case of probe 2a, fluorescence intensities at $392 \mathrm{~nm}$ and $414 \mathrm{~nm}$ decreased progressively but it was accompanied by a remarkable increase in the redshifted fluorescence intensity at $457 \mathrm{~nm}$ (Fig. 4B). In probe $\mathbf{2 b}$, the intensity of the peak at $397 \mathrm{~nm}$ decreased progressively with a concomitant increase in the intensity of the redshifted peak at $463 \mathrm{~nm}$ (Fig. 4D). A well-defined iso emissive point in the emission spectra suggested that the only reaction was the binding of ligand with the proton. We think that the emergence of new emission peak at the higher wavelength is due to the formation of ICT which arises due to the protonation of the probes (Fig. 5). Furthermore, the shift of two emission wavelengths are large $(\Delta F=65 \mathrm{~nm}$ for $2 \mathbf{a} ; \Delta F=66 \mathrm{~nm}$ for $2 \mathbf{b})$ which contributes to the accurate measurement of emission intensities. As shown in the Table 1, addition of TFA to the probe 2a increased the stokes shift from $125 \mathrm{~nm}$ to $196 \mathrm{~nm}$ for probe 2a and from $130 \mathrm{~nm}$ to $190 \mathrm{~nm}$ for probe $2 \mathbf{b}$. It was noted that the fluorescence quantum yields $\left(\Phi_{\mathrm{f}}\right)$ for the probes $\mathbf{2 a}$ and $\mathbf{2 b}$ decreased significantly for the protonated form (Table 1). The linear ratiometric fluorescence response of the probes towards TFA concentration is of particular importance. The ratio of the emission intensity $I_{392} / I_{457}$ for $\mathbf{2 a}$ and $I_{397} / I_{463}$ for $\mathbf{2 b}$ has linear correlation with the concentration of TFA. The linear equation was found to be $y=0.0000096+0.4$ for $2 \mathrm{a}$ and $y=0.000023+$ $(-0.33)$ for $2 \mathbf{b}$ (Fig. $\mathrm{S} 22 \dagger$ ) indicating that probes $2 \mathbf{a} \& 2 \mathbf{b}$ can quantitatively detect $\mathrm{H}^{+}$concentration. Furthermore, clear fluorescence color change was observed for compound 2 a from blue to green while adding TFA as shown in the Fig. 5 .

\section{Reversibility of the receptor}

The possible deprotonation of the probe $\mathbf{2 a}$ and $\mathbf{2} \mathbf{b}$ and its fluorescence spectrum over the addition of TEA was monitored. On addition of TEA, the fluoresce spectrum of protonated species $\mathbf{2} \mathbf{a}-\mathbf{H}^{+}$and $\mathbf{2} \mathbf{b}-\mathbf{H}^{+}$got completely reversed and fluoresce

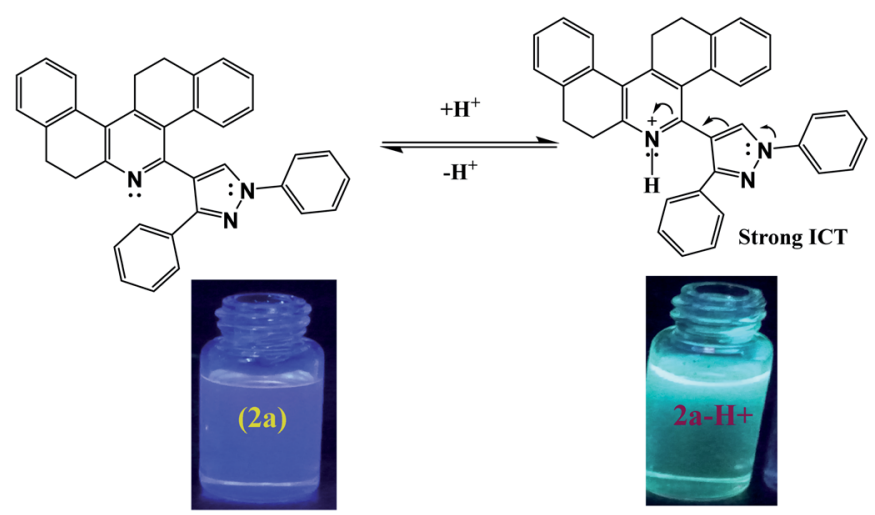

Fig. 5 Mechanism of protonation of compound $2 a$ and the fluorescence color change of the probe over acidification.
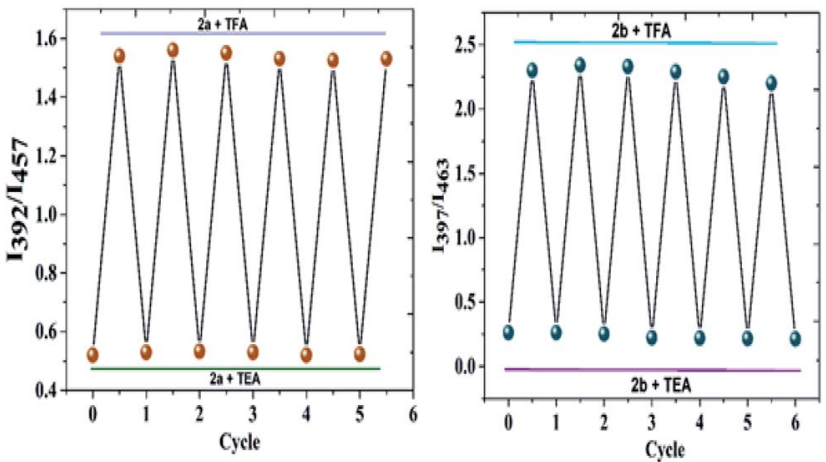

Fig. 6 The fluorescence intensity ration of $2 a$ and $2 b$ upon consecutive addition of TFA and TEA for up to six cycles.

spectrum almost similar to that of free $\mathbf{2 a}$ and $\mathbf{2 b}$ was obtained (Fig. S23 $\dagger$ ). The reversible behaviour of the probe $\mathbf{2 a}$ and $\mathbf{2 b}$ is shown in Fig. 6. The fluorescence of the protonation and deprotonation states for both the probes was reversed for up to six cycles without much variation in the intensity of fluorescence. Hence, this probe can be used multiple times to analyse the proton concentration.

\section{Emission properties of the probes towards $\mathbf{p H}$}

The fluorescence spectroscopic property of the probes was studied in different $\mathrm{pH}$ buffers containing 50\% ACN. Probe $2 \mathrm{a}$ exhibited fluorescence emission at $392 \mathrm{~nm}$, and when $\mathrm{pH}$ of the buffer was higher than 7.0 no new emission bands were observed. As shown in the Fig. 7, when the $\mathrm{pH}$ of the medium was decreased from 7 to 1 , gradual emergence of new emission peak was observed at $457 \mathrm{~nm}$. In addition, the fluorescence emission of the compounds changed from blue to yellowish green under UV light irradiation (Fig. 7C) suggesting the potential of the probe $2 \mathrm{a}$ to sense the different $\mathrm{pH}$ conditions of

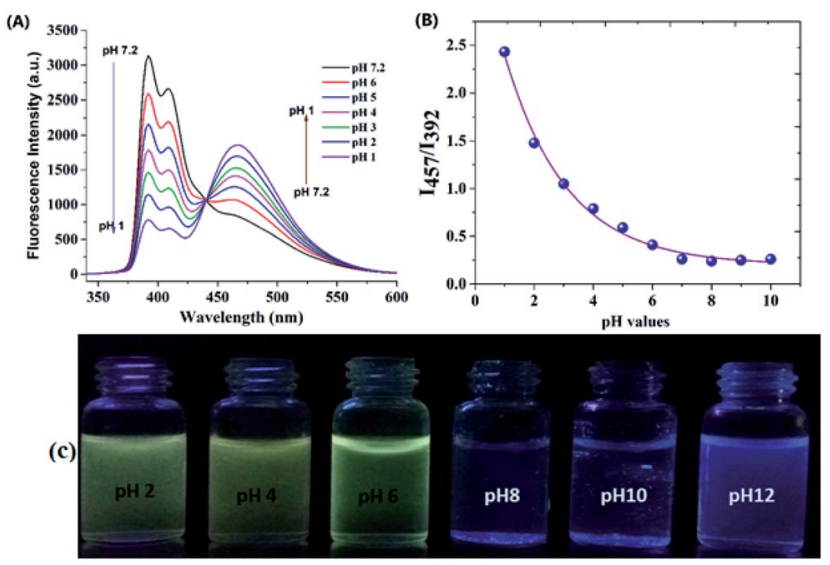

Fig. 7 (A) The fluorescence spectra of compound $2 a\left(\lambda_{\text {ex }}=267 \mathrm{~nm}, 2\right.$ $\times 10^{-4} \mathrm{M}$ ) in acetonitrile: buffer mixture at different $\mathrm{pH}$. (B) Boltzmann fitting curve of fluorescence intensity ratio $\left(/_{457} / /_{392}\right)$ vs. different $\mathrm{pH}$ values in buffer solutions. (C) Fluorescence color change of $2 \mathrm{a}$ under various $\mathrm{pH}$ solution. 
the medium. The $\mathrm{p} K_{\mathrm{a}}$ was calculated at abrupt points by plotting Boltzmann fitting curve as shown in the Fig. $7 \mathrm{~B}$. The $\mathrm{p} K_{\mathrm{a}}$ was found to be $3.12 \pm 0.02$ indicating the excellent $\mathrm{pH}$ sensing ability of probe $\mathbf{2 a}$.

Even though probe $\mathbf{2 b}$ showed significant fluorescence ratiometric behaviour with TFA in chloroform, its effect on $\mathrm{pH}$ was relatively less. This could due to the water intolerance of the probe $\mathbf{2 b}$.

\section{The optical properties in different solvents}

We try to optimize the quantum efficiency of compound $2 \mathbf{a}$ and 2b in different types of solvents. This showed that distinct interaction of the molecules in non-polar and polar solvents. While increasing the solvent polarity, the spectrum showed red shift with lower intensity. It may be due to the dipole interaction between lone pair of pyridine nitrogen and $\mathrm{H}^{+}$ion from polar solvent (Fig. 8) and Table 3.

\section{Selectivity and anti-interference studies}

The selectivity and anti-interference of this probe to $\mathrm{H}^{+}$was examined by measuring the fluorescence spectra of the probes
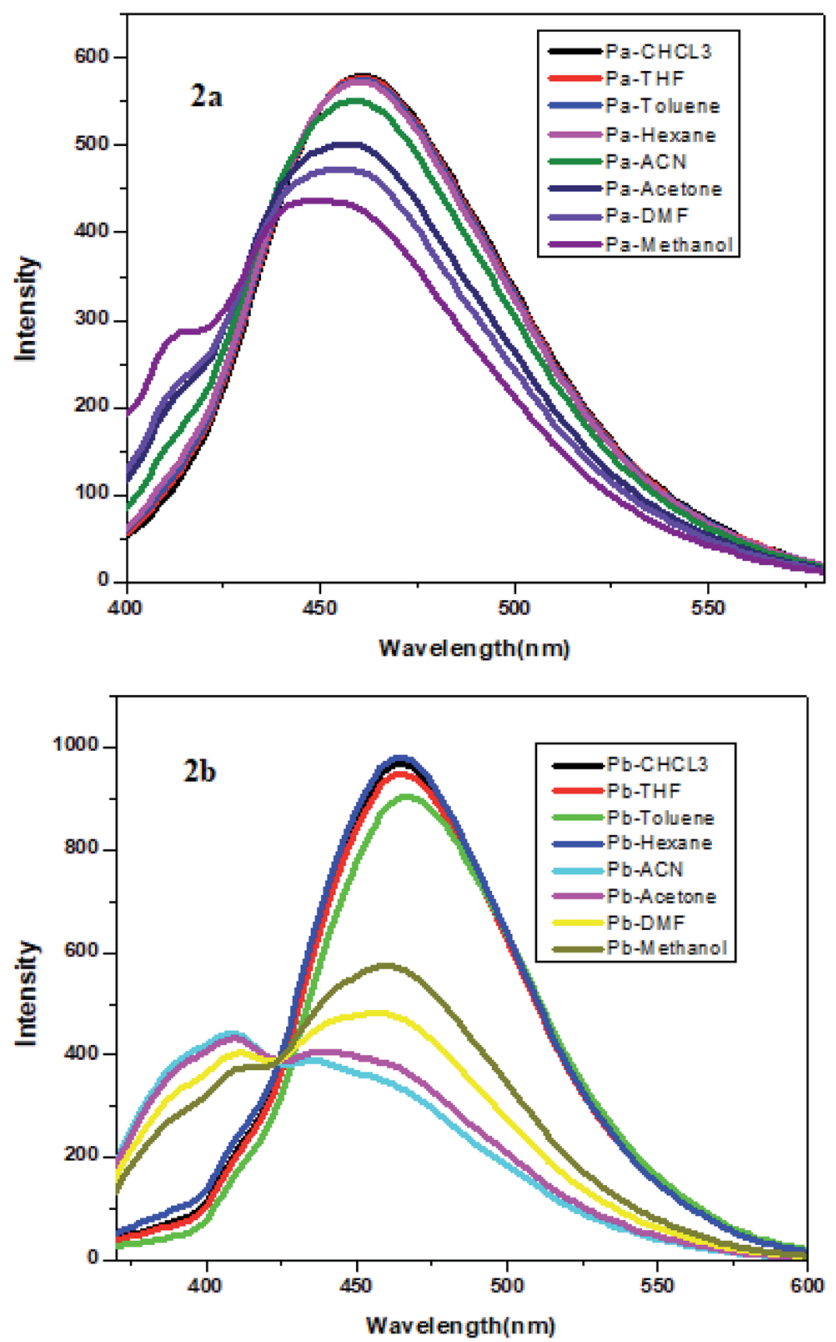

Fig. 8 The solvent effect of $2 a$ and $2 b$.
Table 3 The quantum yield of $2 \mathrm{a}$ and $2 \mathrm{~b}$ in different solvent

\begin{tabular}{|c|c|c|c|c|}
\hline & \multicolumn{2}{|l|}{$\mathrm{Pa}$} & \multicolumn{2}{|l|}{$\mathrm{Pb}$} \\
\hline & $\lambda_{\mathrm{em}}(\mathrm{nm})$ & $\Phi_{\mathrm{f}}^{a}$ & $\lambda_{\mathrm{em}}(\mathrm{nm})$ & $\Phi_{\mathrm{f}}^{a}$ \\
\hline \multicolumn{5}{|l|}{ Low polar solvent } \\
\hline $\mathrm{CHCl}_{3}$ & 461.22 & 0.20 & 464.84 & 0.17 \\
\hline THF & 461.22 & 0.18 & 464.84 & 0.17 \\
\hline Toluene & 460.78 & 0.19 & 467.70 & 0.18 \\
\hline Hexane & 460.71 & 0.18 & 464.84 & 0.18 \\
\hline \multicolumn{5}{|l|}{ High polar solvent } \\
\hline Acetonitrile & 459.42 & 0.20 & 408,437 & 0.17 \\
\hline Acetone & 456.26 & 0.18 & 409,440 & 0.17 \\
\hline Dimethelyformate & 455.82 & 0.19 & 399,459 & 0.18 \\
\hline Methanol & 413,449 & 0.18 & 409,461 & 0.18 \\
\hline
\end{tabular}

with competing ions, such as, metal ions $\left(\mathrm{Pb}^{2+}, \mathrm{Ni}^{2+}, \mathrm{Fe}^{2+}, \mathrm{Cu}^{+}\right.$, $\mathrm{Zn}^{2+}, \mathrm{Cd}^{+}, \mathrm{Ag}^{2+}, \mathrm{Pd}^{2+}, \mathrm{Hg}^{2+}, \mathrm{Cu}^{2+}, \mathrm{Cr}^{3+}, \mathrm{Fe}^{3+}, \mathrm{Al}^{3+}, \mathrm{Hg}^{2+}$ ), anions $\left(\mathrm{F}^{-}, \mathrm{Cl}^{-,} \mathrm{I}^{-}, \mathrm{HCO}_{3}{ }^{-}, \mathrm{CH}_{3} \mathrm{COO}^{-}\right)$and thiol involved biomolecules (cysteine). As shown in Fig. 9, other ions and small molecules induced no obvious change or quenching effect on the fluorescence spectra of the probe 2 a. Similar selectivity of $\mathrm{H}^{+}$was observed for compound $\mathbf{2 b}$ also (Fig. S24 $\dagger$ ). The fluorescence sensing study of the probe towards $\mathrm{H}^{+}$was also studied in the presence the ions mentioned above. The results demonstrated that the presence of other ion had no influence on the detection $\mathrm{H}^{+}$. These results suggest that the probes have good selectivity and anti-interference ability towards the detection of $\mathrm{H}^{+}$.

\section{Theoretical results}

Theoretical calculations were performed using DFT and TDDFT methods in phases, the gas phase and the solution phase, for understanding the structural properties of the investigated systems. The optimized geometry of probe $\mathbf{2 a}$ is shown in

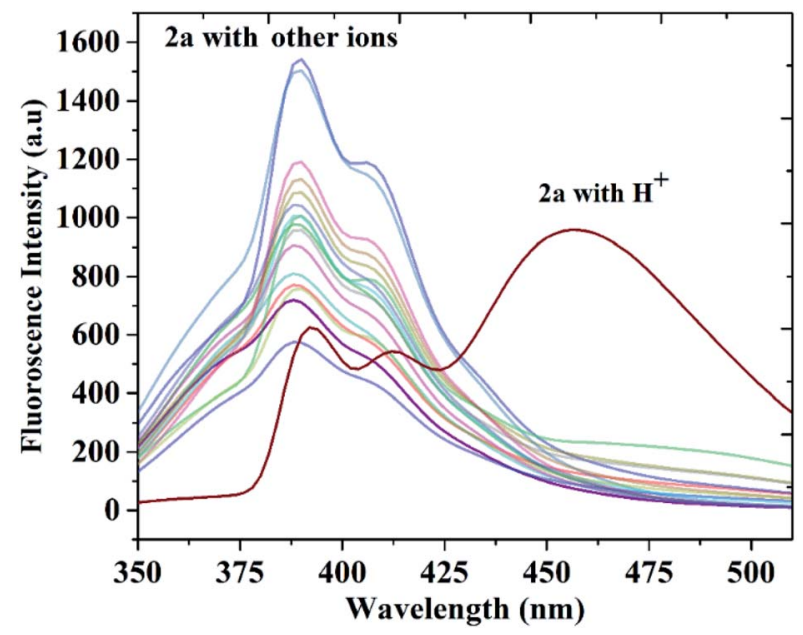

Fig. 9 The fluorescence spectra of probe $2 \mathrm{a}\left(2 \times 10^{-5} \mathrm{M}\right)$ over the addition of various testing ion (10.0 equiv. for each ion) in $1: 1 \mathrm{PBS}$ buffer $(\mathrm{pH}=7.4)$ and acetonitrile solvent. The $\lambda_{\text {ex }}$ was set to be $267 \mathrm{~nm}$. 


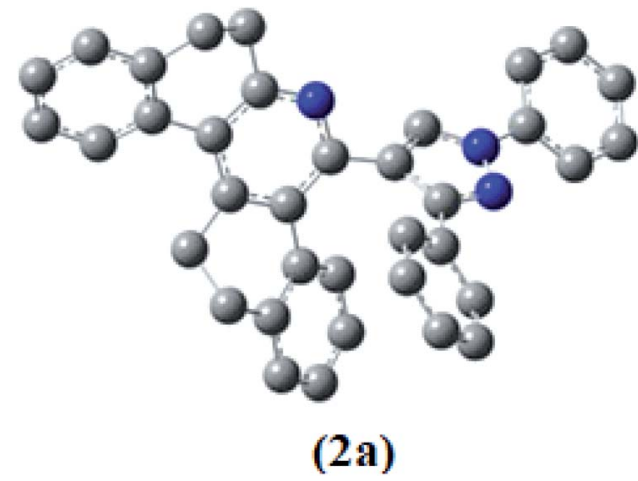

Fig. 10 The optimized geometry of $2 a$ at B3LYP/6-31+G* level of theory. The implicit solvation model is used for structure optimization in TFA solvent. All hydrogen atoms are omitted for clarity.

Fig. 10. The energy minimized structure of probe $\mathbf{2 b}$ is shown in Fig. S25. $\uparrow$ Table 2 pre-sets the optimized geometrical parameters of probe $2 \mathbf{a}$ at B3LYP/6-31+G* level of theory by comparing them with the available crystal structure. The selected structural parameters as shown in Table 4 are in good agreement with crystal geometry. The calculated bond length of N2-N3 was $\sim 1.356 \AA$ and bond angle N2-C23-C22 was $\sim 107.6^{\circ}$ for probe 2a. Notable deviations in the calculated structural parameter were not observed at B3LYP/6-31+G* level of theory. Further,

Table 4 The selected structural parameters of $2 a$ at B3LYP/6-31+G* level of theory and corresponding crystal data. The numbering scheme is followed as given for the probe $2 \mathrm{a}$ in Fig. 2

\begin{tabular}{|c|c|c|}
\hline \multirow[b]{3}{*}{ Structural parameters } & \multicolumn{2}{|l|}{$2 \mathbf{a}$} \\
\hline & B3LYP/6-31+G* & Crystal \\
\hline & Bond length $(\AA)$ & \\
\hline C1-N1 & 1.333 & 1.334 \\
\hline $\mathrm{C} 24-\mathrm{N} 2$ & 1.422 & 1.422 \\
\hline $\mathrm{C} 23-\mathrm{N} 2$ & 1.363 & 1.352 \\
\hline C30-N3 & 1.338 & 1.324 \\
\hline C21-N1 & 1.349 & 1.349 \\
\hline C30-C31 & 1.477 & 1.471 \\
\hline $\mathrm{C} 21-\mathrm{C} 22$ & 1.484 & 1.473 \\
\hline N2-N3 & 1.357 & 1.356 \\
\hline C18-C19 & 1.406 & 1.396 \\
\hline
\end{tabular}

\begin{tabular}{|c|c|c|}
\hline \multirow[b]{3}{*}{ Structural parameters } & \multicolumn{2}{|l|}{$2 a$} \\
\hline & B3LYP/6-31+G* & Crysta \\
\hline & Bond angle $\left(^{\circ}\right)$ & \\
\hline $\mathrm{N} 1-\mathrm{C} 1-\mathrm{C} 2$ & 117.3 & 124.1 \\
\hline $\mathrm{C} 1-\mathrm{C} 2-\mathrm{C} 3$ & 109.8 & 110.5 \\
\hline N2-C23-C22 & 107.6 & 108 \\
\hline $\mathrm{C} 29-\mathrm{C} 24-\mathrm{N} 2$ & 119.7 & 119.7 \\
\hline C25-C24-N2 & 120 & 120.6 \\
\hline C36-C31-C30 & 121 & 121.4 \\
\hline N1-C21-C20 & 122 & 122.4 \\
\hline
\end{tabular}

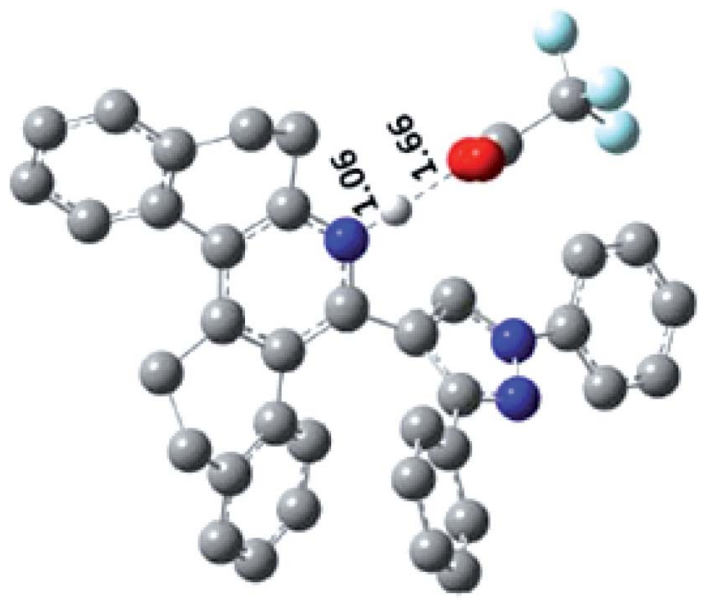

2A-TFA

Fig. 11 The optimized geometries of 2a with TFA solvent, named as 2a-TFA. The proposed solvent interaction is studied explicitly by considering one TFA molecule. In addition to that, the implicit solvation model is used for structure optimization in TFA solvent at B3LYP/ $6-31+G *$ level of theory. All hydrogen atoms are omitted for clarity.

probes $\mathbf{2 a}$ and $\mathbf{2 b}$ were explicitly treated with one TFA (considered as 2a-TFA and 2b-TFA respectively) and 2a-TFA and 2b-TFA which were optimized with implicit solvation model. The optimized electronic structures of 2a-TFA and 2b-TFA are shown in Fig. 10 and S26† respectively (Fig. 11).

The TDDFT calculations were carried out for accounting excitation energy in TFA solvent using B3LYP/6-31+G* level of theory. The calculated UV-vis absorption wavelength of FMO pairs responsible for the excitation energy and its contribution in percentage is provided in Table 5. Compound 2a showed itself as having electron rich pyrazole moiety, exhibiting excitation energy $326.3 \mathrm{~nm}$, whereas $\mathbf{2} \mathbf{a}+\mathbf{H}^{+}$, the acceptor pyridinium ion exhibited excitation energy $367.23 \mathrm{~nm}$ due to elongated conjugation with HUMO-LUMO transition. Similarly, the observed excitation energy difference between $\mathbf{2 b}$ and $\mathbf{2 b}+\mathbf{H}^{+}$ was $59.53 \mathrm{~nm}$ with same HUMO-LUMO transition.

The Frontier Molecular Orbital's (FMO) density plots of probe $2 \mathrm{a}$ and 2a-TFA are shown in Fig. 12. Fig. S27† shows the FMO density plots of probe $2 \mathbf{b}$ and $2 \mathbf{b}$-TFA. In the highest molecular orbital (HOMO), the electron density was mainly accumulated on pyrazole coordinated pyridine ring but in the lowest unoccupied molecular orbital (LUMO), it was localized on phenanthridine moiety. The calculated UV-vis spectra of $\mathbf{2 a}$, 2b, 2a-TFA and 2b-TFA in TFA medium are shown in Fig. 13.

To understand the photo-physical properties of investigated systems, the absorption bands $\mathbf{2 a}$ and $\mathbf{2 a}+\mathbf{H}^{+}$were observed in gas phase and also in the acidic medium (TFA). The experimental results of the probe 2a showed two peaks at $267 \mathrm{~nm}$ and $320 \mathrm{~nm}$. The absorption intensity got enhanced to $279 \mathrm{~nm}$ and $315 \mathrm{~nm}$ when it was treated with solvent TFA. The theoretically calculated UV-vis wavelength absorption maximum, $\lambda_{\max }(\mathrm{nm})$ which was obtained by employing the TDDFT method in gas phase and also in TFA medium are provided in Table 6 . The MO 
Table 5 Calculated UV-vis absorption wavelength of FMO pairs responsible for the excitation energy and its contribution in percentage. All single point TDDFT calculations employed in optimized structures in TFA solvent medium

\section{PCM/B3LYP/6-31+G* in TFA solvent}

\begin{tabular}{llll} 
Structures & $\begin{array}{l}\text { Excitation energy } \\
(\mathrm{nm})\end{array}$ & FMO transition & $\begin{array}{l}\text { FMO pair contribution } \\
(\%)\end{array}$ \\
\hline 2a & 326.13 & HOMO $\rightarrow$ LUMO & 69 \\
2b & 336.44 & HOMO $\rightarrow$ LUMO & 70 \\
2a-TFA & 367.23 & HOMO $\rightarrow$ LUMO & 70 \\
2b-TFA & 395.97 & HOMO $\rightarrow$ LUMO & 70
\end{tabular}

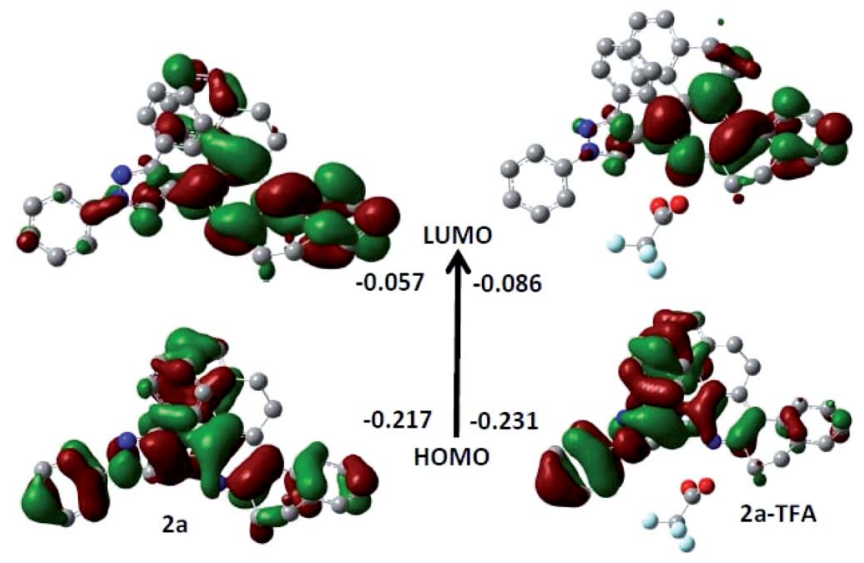

Fig. 12 FMO pairs responsible for the excitation energy in $2 a$ and $2 a-$ TFA. All orbitals are obtained from PCM/B3LYP/6-31+G* single point calculation in TFA solvent. Isovalue for surface $=0.02$. All hydrogen atoms are omitted for clarity.

transition, which was responsible for $\lambda_{\max }$ in $2 \mathbf{a}$ and $2 \mathbf{a}-\mathbf{T F A}$, is shown in Fig. 14.

In 2a, MO transition occurred from HOMO-2 to LUMO but in the case of 2a-TFA, the MO transition happened from

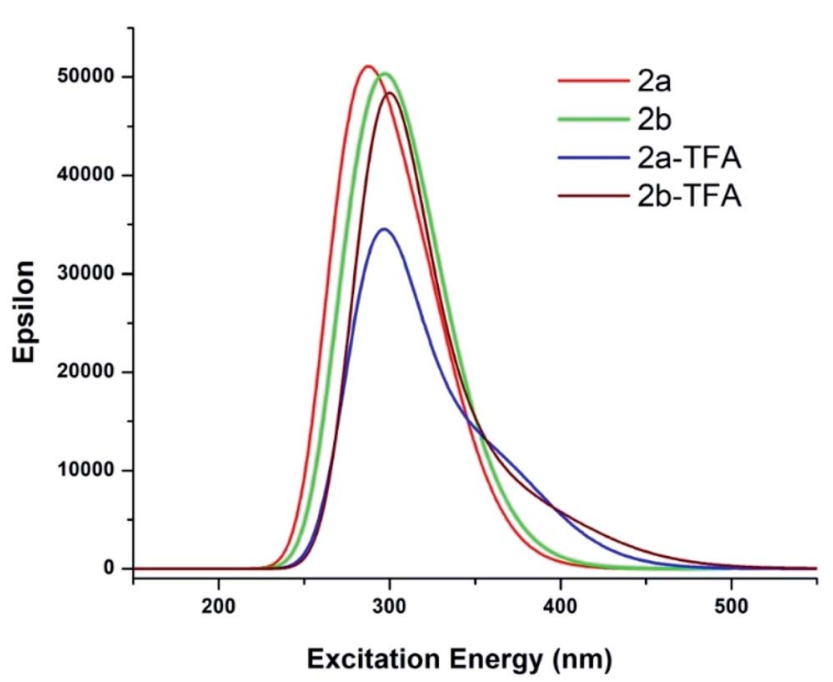

Fig. 13 UV-vis spectra of investigated molecules in TFA medium. All single point TDDFT calculations employed in optimized structures in TFA solvent medium at PCM/B3LYP/6-31+G* level of theory.

Table 6 Calculated UV-vis absorption wavelength of FMO pairs responsible for the excitation energy and its contribution in percentage. All single point TDDFT calculations employed in optimized structures in TFA solvent medium

\begin{tabular}{|c|c|c|c|c|}
\hline \multirow[b]{3}{*}{ Structures } & \multirow[b]{3}{*}{ MO transition } & \multicolumn{2}{|c|}{ B3LYP/6-31+G* } & \multirow{3}{*}{$\begin{array}{l}\text { Exp. } \\
\lambda_{\max }(\mathrm{nm})\end{array}$} \\
\hline & & \multicolumn{2}{|l|}{$\lambda_{\max }(\mathrm{nm})$} & \\
\hline & & Gas phase & TFA & \\
\hline $2 a$ & HOMO-2 $\rightarrow$ LUMO & 301 & 285 & 267,320 \\
\hline 2a-TFA & $\mathrm{HOMO} \rightarrow \mathrm{LUMO}+1$ & 289 & 294 & 279,315 \\
\hline $2 \mathbf{b}$ & $\mathrm{HOMO} \rightarrow \mathrm{LUMO}+2$ & 306 & 305 & 267,320 \\
\hline 2b-TFA & $\mathrm{HOMO} \rightarrow \mathrm{LUMO}+2$ & 298 & 296 & 265,318 \\
\hline
\end{tabular}

HOMO-2 to LUMO+1. Fig. S28† shows MO transitions which are responsible for the corresponding $\lambda_{\max }$ values in $\mathbf{2 b}$ and $\mathbf{2 b}$ TFA. This happens because of HOMO to LUMO+2 in both cases. The computed results on MO transitions showed the single
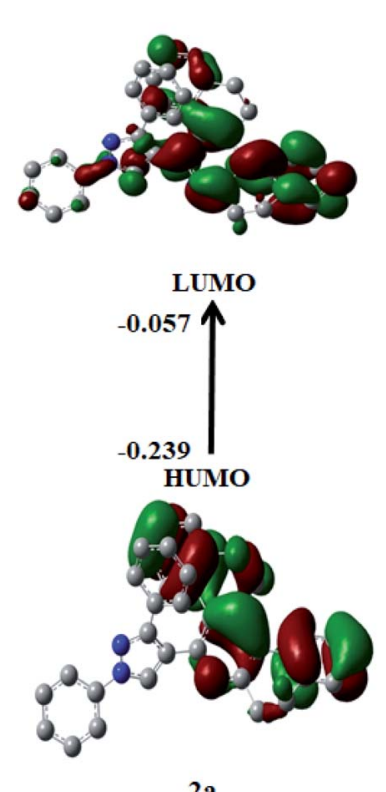

Fig. 14 The MO pairs responsible for UV-vis wavelength absorption maximum, $\lambda_{\max }(\mathrm{nm})$ in $2 \mathrm{a}$ and $2 \mathrm{a}-\mathrm{TFA}$. All orbitals are obtained from PCM/B3LYP/6-31+G* single point calculation in TFA solvent. Isovalue for surface $=0.02$. All hydrogen atoms are omitted for clarity. 


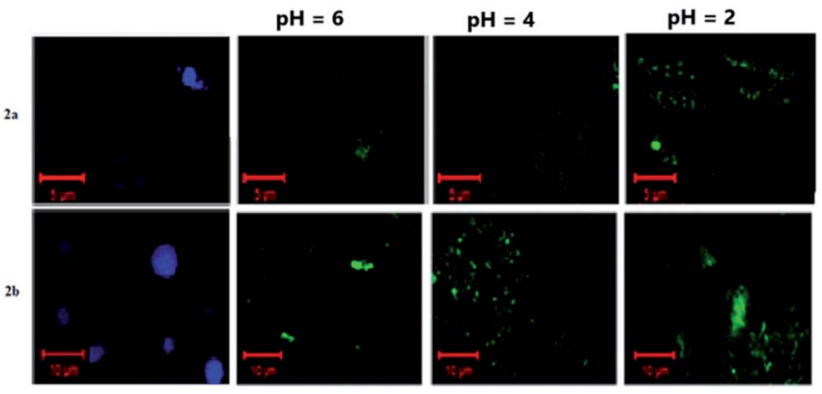

Fig. 15 Fluorescence microscopic images of living $E$. coli cells incubated with probe $2 \mathrm{a}$ and $2 \mathrm{~b}$ for $30 \mathrm{~min}$ at $37^{\circ} \mathrm{C}$ and then incubated with various $\mathrm{pH}$ buffers.

mode of peak at $285 \mathrm{~nm}$ in acidic medium and at $301 \mathrm{~nm}$ in gas phase and the MO transition was associated with HOMO-2 to LUMO for the probe 2a. In TFA, with an explicit treatment with probe 2a, the absorption band increased to $294 \mathrm{~nm}$ with HOMO-2 to LUMO+1 transition. This indicates that the electron density of pyrazole influenced by internal charge transfer in acidic medium, led to the formation of a rigid structure of donor- $\pi$-acceptor conjugation with pyridinium ion. Similarly, the absorption band of probe $\mathbf{2 b}$ and $\mathbf{2 b}+\mathbf{H}^{+}$showed a single mode of peak at $306 \mathrm{~nm}$ in gas phase and $305 \mathrm{~nm}$ in solution phase by dominated HOMO-LUMO+2 transition. The observed absorption band slightly decreased from $298 \mathrm{~nm}$ in gas phase to $296 \mathrm{~nm}$ in TFA, thus accounting for the rigidity that occurred in the attachment of methoxy segment. As discussed above, theoretically computed photo-physical properties corroborated well with experimental data.

\section{Application in living cell $\mathbf{p H}$ imaging}

To demonstrate the $\mathrm{pH}$ sensing ability of the probes inside the cells, Escherichia coli (E. coli) cells were employed for cell imaging $^{50-52}$ at different $\mathrm{pH}$ values. An ionophore nigericin was used in order to allow the $\mathrm{H}^{+}$ions to pass through the cells to maintain the required $\mathrm{pH}$ in the cell. $E$. coli cells were treated with probes in PBS buffer $(\mathrm{pH}=7.4)$ for 30 minutes at $37^{\circ} \mathrm{C}$ and then washed three times with buffer solution of varying $\mathrm{pH}$ levels. The fluorescence microscope images of $E$. coli cells with probes $\mathbf{2 a}$ and $\mathbf{2 b}$ are shown in Fig. 15 . E . coli cells exhibited bright blue color image when intracellular $\mathrm{pH}$ was 7.4, indicating that probes $\mathbf{2 a}$ and $\mathbf{2 b}$ were permeable to the cell membrane, and they successfully internalized into the cells. As shown in the Fig. 15, the bright blue emission of the cell completely vanished when the $\mathrm{pH}$ of the solution was altered from basic to acidic and bright green color was noticed. This cell imaging experiment was in good agreement with the results obtained in the aqueous solution, thus indicating the excellent bioimaging performance of the synthesized probes to detect the change of $\mathrm{pH}$ values in living cells.

Moreover, the cell viability (after incubation) with the E. coli bacteria at different concentration was estimated. The observed data indicates that cell viability remained above $85 \%$ upon incubation. This shows the cytotoxicity was present in negligible amount for compound $\mathbf{2 a}$ and $\mathbf{2 b}$. The observed data were showed in Fig. S29. $\dagger$

\section{Conclusion}

We have synthesized new class of fused phenanthridinepyrazole compounds whose proton sensing ability originates from the induced intra molecular charge transfer mechanism. Probes $\mathbf{2 a}$ and $\mathbf{2 b}$ showed excellent fluorescent ratiometric behaviour over the addition of TFA. Moreover, the fluorescence property of the protonated probe can be reversed several times. The fluorescence of compound 2 a exhibited excellent $\mathrm{pH}$ responsive abilities in the $\mathrm{pH}$ range of 7 to 1 with the $\mathrm{p} K_{\mathrm{a}}$ value at 3.12. Further, probes $\mathbf{2 a}$ and $\mathbf{2 b}$ showed exceptional selectivity towards $\mathrm{H}^{+}$ion and the fluorescence was much less perturbed with other competitive ions and molecules. The acid responsive mechanism of the probes $\mathbf{2 a}$ and $\mathbf{2 b}$ was investigated by DFT and TDDFT methods. The experimentally observed photo-physical properties were well correlated with FMO transitions and their ponding excitation energy. The experiment of living cell imaging of $\mathrm{pH}$ showed remarkable bio-imaging performance of probes $\mathbf{2} \mathbf{a}$ and $\mathbf{2} \mathbf{b}$.

\section{Conflicts of interest}

There is no conflict of interest.

\section{Acknowledgements}

The authors thank VIT Management for funding through seed money (Grand 2018-2019) and DST-FIST and VIT-SIF for FTNMR facility and authors would like to thank Dr R. Srinivasan, SSL, Vellore Institute of Technology for language editing.

\section{Notes and references}

1 H. Ju, W. Kang, J. Zhang, H. Geng, Z. Liu, G. Zhang, Y. Zhao and D.-Q. Zhang, Chem. Mater., 2017, 29, 3580-3588.

2 A. Al Mousawi, F. Dumur, P. Garra, J. Toufaily, T. Hamieh, B. Graff, D. Gigmes, J. P. Fouassier and J. Lalevée, Macromolecules, 2017, 50, 2747-2758.

3 A. Al Mousawi, P. Gaara, X. Sallenave, F. Dumur, J. Toufaily, T. Hamieh, B. Graff, D. Grimes, J. P. Fouassier and J. Lalevée, Macromolecules, 2017, 50, 4913-4926.

4 H.-Y. Chen, G. Schweicher, M. Planells, S. Ryno, K. Broch, A. White, D. Simatos, M. Little, C. Jellett, S. Cryer, A. Marks, M. Hurhangee, J.-L. Bredas, H. Sirringhaus and I. McCulloch, Chem. Mater., 2018, 30, 7587-7592.

5 V. Prakasam, F. Di Giacomo, R. Abbel, D. Tordera, M. Sessolo, G. Gelinck and H. J. Bolink, ACS Appl. Mater. Interfaces, 2018, 10, 41586-41591.

6 Z. Yang, Z. Mao, Z. Xie, Y. Zhang, S. Liu, J. Zhao, J. Xu, Z. Chi and M. P. Aldred, Chem. Soc. Rev., 2017, 46, 915-1016.

7 X. Yang, G. Zhou and W.-Y. Wong, Chem. Soc. Rev., 2015, 44, 8484-8575.

8 J. Tagare and S. Vaidyanathan, J. Mater. Chem. C, 2018, 6, 10138-10173. 
9 W. Wu, C. Z. Jiang and V. A. L. Roy, Nanoscale, 2016, 8, 19421-19474.

10 X. He, Z. Zhao, L.-H. Xiong, P. F. Gao, C. Peng, R. S. Li, Y. Xiong, Z. Li, H. H.-Y. Sung, I. D. Williams, R. T. K. Kwok, J. W. Y. Lam, C. Z. Huang, N. Ma and B. Z. Tang, J. Am. Chem. Soc., 2018, 140, 6904-6911.

11 D. Xu, H. Zou and M. Liu, J. Colloid Interface Sci., 2017, 508, 248-253.

12 J. Li, X. Zhen, Y. Lyu, Y. Jiang, J. Huang and K. Pu, ACS Nano, 2018, 12, 8520-8530.

13 J. Qi, C. Sun, D. Li, H. Zhang, W. Yu, A. Zebibula, J. W. Y. Lam, W. Xi, L. Zhu, F. Cai, P. Wei, C. Zhu, R. T. K. Kwok, L. L. Streich, R. Prevedel, J. Qian and B. Z. Tang, ACS Nano, 2018, 12, 7936-7945.

14 V. Aruna, V. Aruna and Y. Gao., ACS Appl. Bio Mater., 2018, 1, 298-309.

15 K. Y. Zhang, Q. Yu, H. Wei, S. Liu and Q. Zhao, Chem. Rev., 2018, 118, 1770-1839.

16 S. M. A. Fateminia, Z. Mao, S. Xu, Z. Yang, Z. Chi and B. Liu, Angew. Chem., 2017, 56, 12160-12164.

17 J. F. d. S. Petruci, P. C. Hauser and A. A., Sens. Actuators, B, 2018, 268, 392-397.

18 N. Kwon, Y. Hu and J. Yoon, ACS Omega, 2018, 3, 1373113751.

19 J. F. d. S. Petruci and A. A. Cardoso, Anal. Chem., 2016, 88, 11714-11719.

20 M. Lee, Y.-C. Jang, W. Den and P. Kuo, Synthesis of Fluorogenic Chemosensors for $\mathrm{Hg}^{2+}$ Detection Using Naphthalimide Derivatives, American Chemical Society, 2014, vol. 1184, pp. 49-69.

21 X. Zhou and S. Lee, Chem. Rev., 2015, 15, 7944-8000.

22 Z. Simić, Z. Stanić and M. Antonijevic, J. Braz. Chem. Soc., 2010, 22, 709-717.

23 N. Balázs and P. Sipos, Carbohydr. Res., 2007, 342, 124-130.

24 J. Fan, C. Lin, H. Li, P. Zhan, J. Wang, S. Cui, M. Hu, G. Cheng and X. Peng, Dyes Pigm., 2013, 99, 620-626.

25 S. Radunz, H. R. Tschiche, D. Moldenhauer and U. ReschGenger, Sens. Actuators, B, 2017, 251, 490-494.

26 K. Aggarwal and J. M. Khurana, J. Photochem. Photobiol., A, 2015, 307-308, 1-18.

27 E. Faggi, J. Serra-Vinardell, M. D. Pandey, J. Casas and G. Fabriàs, Sens. Actuators, B, 2016, 234, 633-640.

28 A. Thottiparambil, P. R. A. Kumar and L. Chakkumkumarath, RSC Adv., 2014, 4, 56063-56067.

29 M. Tian, X. Peng, J. Fan, J. Wang and S. Sun, Dyes Pigm., 2012, 95, 112-115.

30 D. Aigner, S. M. Borisov, F. J. O. Fernández, J. F. Fernández Sánchez, R. Saf and I. Klimant, Talanta, 2012, 99, 194-201.
31 Y. Chen, C. Zhu, J. Cen, Y. Bai., W. He and Z. Guo, Chem. Sci., 2015, 6, 3187-3194.

32 P. Guo, L. Liu, Q. Shi, C. Yin and X. Shi, J. Mol. Struct., 2017, 1130, 150-155.

33 J. Fan, C. Lin, H. Li, P. Zhan, J. Wang, S. Cui, M. Hu, G. Cheng and X. Peng, Dyes Pigm., 2013, 99, 620-626.

34 R. Shi, L. Huang, X. Duan, G. Sun, G. Yin, R. Wang and J. Zhu, Anal. Chim. Acta, 2017, 988, 66-73.

35 S. Munusamy and S. Kulathu Iyer, Tetrahedron: Asymmetry, 2016, 27, 492-497.

36 S. Munusamy, V. P. Muralidharan and S. K. Iyer, Sens. Actuators, B, 2017, 250, 244-249.

37 S. K. Munusamy, K. Thirumoorthy, V. Panyam Muralidharan, U. Balijapalli and S. Kulathu Iyer, Sens. Actuators, B, 2017, 244, 175-181.

38 M. Venkatesan and S. Kulathu Iyer, Sens. Actuators, B, 2018, 267, 373-380.

39 M. Venkatesan and K. I. Sathiyanarayanan, Sens. Actuators, B, 2018, 267, 373-380.

40 V. P. Gupta, in Principles and Applications of Quantum Chemistry, ed. V. P. Gupta, Academic Press, Boston, 2016, pp. 155-194.

41 A. Charaf-Eddin, A. Planchat, B. Mennucci, C. Adamo and D. Jacquemin, J. Chem. Theory Comput., 2013, 9(6), 27492760.

42 A. D. Becke, Phys. Rev. A: At., Mol., Opt. Phys., 1988, 38, 30983100.

43 C. Lee, W. Yang and R. G. Parr, Phys. Rev. B: Condens. Matter Mater. Phys., 1988, 37, 785-789.

44 J. Tomasi, B. Mennucci and R. Cammi, Chem. Rev., 2005, 105, 2999-3093.

45 R. E. Stratmann, G. E. Scuseria and M. J. Frisch, J. Chem. Phys., 1998, 109, 8218-8224.

46 M. E. Casida, C. Jamorski, K. C. Casida and D. R. Salahub, J. Chem. Phys., 1998, 108, 4439-4449.

47 M. J. Frisch. G. W. Trucks. H. B. Schlegel. G. E. Scuseria. M. A. Robb, J. R. Cheeseman, et al., Gaussian 09, Gaussian, Inc., Wallingford, CT, USA, 2009.

48 T. Keith and J. Millam, GaussView, version 5.0.9, Semichem Inc., Shawnee Mission, KS, USA, 2009.

49 K. S. Pawan, C. Navneet, K. Pawan, S. Chetan and R. A. Kamal, Eur. J. Med. Chem., 2011, 46, 1425.

50 S. Xia and H. Liu, Bioconjugate Chem., 2018, 29, 1406-1418. 51 H. Liu, R. L. Luck, H.-M. Lee and J. Wang, J. Mater. Chem. B, 2019, 7, 198-209.

52 X. Song and X. Liu, Anal. Chem., 2017, 89, 7038-7045. 